\title{
The Association between Lifestyle, Anthropometric Measurements, and Obesity in University Students
}

\author{
Asmaa F. Hamouda ${ }^{1,2}$ \\ 1. Department of biochemistry, University of Alexandria, Alexandria 21111, Egypt \\ 2. Department of chemistry, University of Al Leith-Umm Al-Qura, Mecca, 21955, Saudi Arabia
}

\begin{abstract}
Nutritional Assessment is the process of identifying characteristics known to associated with nutrition problems. Certain foods with chemical additives disguised as food can cause muscle and joint pain associated with arthritis, gout, fibromyalgia, obesity, cancer and others. Avoiding these foods can reduced inflammation, thus prevent obesity, cancer, and another disease. The target of the study was to find a relation between food type, anthropometric parameters and obesity-related diseases for university students in College-Al Leith-Umm al-Qura University, Saudi Arabia. The purpose is to identify populations (100 subjects women, aged: 17-30 year, using questionnaire) who are malnourished or at nutritional risk. Participants were divided into normal-weight and obese groups. The different methods are used to collect data including: 1. Anthropometric, 2. Dietary: Nutritional History (Current Intake), 3. FFQ (Food frequency questionnaire). There is a significant association between certain food type, anthropometric parameters, obesity as well as other diseases including (vitamin D deficiency, kidney problems, bone pain, general weakness, thyroid problems, infertility.
\end{abstract}

Key words: Nutritional assessment, obesity, anthropometric parameters.

\section{Introduction}

Nutritional assessment is including anthropometric measurements, biological profile, nutrients, food and eating habits analysis [1-3]. Obesity is a chronic metabolic disease that resulted from a nutritional imbalance that characterized by excessive fat deposition in the body. Obesity is accompaniment with a high rate of morbidity and early mortality if left untreated, which increases the risk of developing heart diseases, diabetes, and many types of cancer [4-7].

The first step in collecting data on the nutritional status of a participant is to obtain data on past diet, nutritional habits and medical history using questionnaires [8-10]. The second step in obesity assessment is anthropometric measurements such as BMI (body mass index), WC (waist circumference), WHR (waist to hip ratio), WHtR (waist to height ratio) and others [11, 12]. BMI (Body mass index) is a standard unit that tells if we are at an underweight,

Corresponding author: Asmaa F. Hamouda, Ph.D., assistant professor in the Umm Al-Qura University in Mecca in Saudi Arabia, research field: biochemistry. normal weight, overweight, or obese. In adults, a BMI equal, $<18.0 \mathrm{~kg} / \mathrm{m}^{2}$ in women and $<19.0 \mathrm{~kg} / \mathrm{m}^{2}$ in men for underweight. BMI equal, $18.0-23.9 \mathrm{~kg} / \mathrm{m}^{2}$ in women and $19.0-24.9 \mathrm{~kg} / \mathrm{m}^{2}$ in men for normal weight. BMI equal, 24.0-28.9 kg/m ${ }^{2}$ in women and 25.0-29.9 $\mathrm{kg} / \mathrm{m} 2$ in men for overweight; while BMI > 29.0 $\mathrm{kg} / \mathrm{m} 2$ in women and $>30.0 \mathrm{~kg} / \mathrm{m}^{2}$ in men for obesity [12-14]. WC is a stronger an accurate predictor of visceral fat, and obesity, either alone or in combination with BMI. WC classified $(<94,94-102$, and $>102 \mathrm{~cm}$ in men; < 80, 80-88, and $>88 \mathrm{~cm}$ in women) [13-16]. Our study is the assessment of lifestyle and anthropometric measurements that classification participants into categories of nutritional status according to developed references range.

\section{Materials and Methods}

\subsection{Materials}

\subsubsection{Study Population}

Personal interview protocols developed by the questions answered about the volunteers' current 
health status and were included in the study. The total number of participants was 100 female (17 to 35 year). Inclusion criteria a body mass index ranged from 22 to $37 \mathrm{~kg} / \mathrm{m}^{2}$ while reference controls required having a BMI 18.5-25 $\mathrm{kg} / \mathrm{m}^{2}$. Participants divided into normal-weight (70 female) and obese groups (30 female). No woman was pregnant in our study. The plurality of the participants was from College-Al Leith-Umm al-Qura University, Saudi Arabia. The assessment took place in the period April-June 2015. The protocol approved by the University ethics committee.

\subsection{Methods}

\subsubsection{Anthropometric}

The subjects' weights and heights measured on a single calibrated scale (SRScales, SR Instruments). Other data collected included waist size, Neck, Hip and self-reported medical history. Anthropometric parameters take while the subject was standing erect and barefoot. The measure of height and weight take place by conventional methods. We calculated BMI (body mass index) by the formula: weight in $\mathrm{kg}$ (kilograms) divided by height in $\mathrm{m}^{2}$ (square meters). The Body Fat (\%) calculated by the method of U.S. Navy. Waist circumference WC $(\mathrm{cm})$, the visceral body fat = waist: hip ratio.

2.2.2. Main Methods to Collect Data on Dietary Intake:

Dietary Nutritional History (Current Intake) and FFQ (food frequency questionnaire) is assessment by:

Nutritional History and Food Frequency

Nutritional history and food frequency information collected during the interview with university students. Questionnaire questions that asked to obtain a complete Nutritional History are varying by the information [8-10].

Sample of Nutritional History Questions:

1. How many pounds you gained or lost over the last year?

2. How many meals do you eat a day? Have many snacks?

3. Have you following any regimen? (If yes, which ones and why?)

4. Are there any foods or groups of foods that you dislike, avoid or are allergic?

5. Are you taking any vitamin/mineral supplements or dietary supplements (Herbals/food replacement products)? (If yes, which ones and why?). Record the vitamin $\mathrm{D}$ intake and thyroid medication to determine a risk of bone, thyroid, and infertility diseases [8-10].

6. also, if chronic disease appears to the students own or their family's medical history, expand your inquiries to explore food intake for nutritional risk factors for these diseases. The diseases include (Vitamin D deficiency, kidney problems, bone pain, general weakness, thyroid problems, infertility and others.

Questionnaires of starvation and fullness.

The subjects records rated their daily hunger and satiety $1.5 \mathrm{~h}$ after every meal) [17, 18]. Hunger measured with the question "How hungry did you feel today?" the scale writes on the left by "full" and on the right by "starving." Hunger and fullness were also rated immediately before and after every meal.

Food Craving and Preference Questionnaire.

The subjects record their food craving and preference according to the inventory [19-21]. The subjects was developed to provide a reliable and valid assessment of cravings and preference for different types of foods, group one including unhealthy food such as (High Fats, Sweets, Carbohydrates/Starches, and Fast Food Pizza, French fries, cake doughnuts and cookies, Pepsi cola and sugary drinks, and a traditional staple food called "kabsa" that includes white rice, saturated fat, and red meat or fried chicken with skin) and group two including healthy food such as fruit, vegetable, fish, low-fat milk products and whole grain for, both normal and obese subjects. To avoid effects of a menstrual cycle, Female Students in the menstrual period don't participate in this study. Scientist reported 
that endogenous and exogenous hormones as well as menstrual cycle influence and increase food intake, preference and cravings [22, 23].

\subsubsection{Statistic}

Data is analysis using IBM SPSS software package version 20.0. Quantitative data expressed by mean and standard deviation. For normally distributed data, comparisons between normal and obese treatment were done using paired t-test. The significance of the obtained results analyzed at the 5\% level. (SPSS version 20.0).

\section{Results}

\subsection{Anthropometric Measurements}

Table 1 shows the general characterization of inclusion criteria of 100 female's participants that divided to two groups: normal (70 females) and obese type II (30 females). Anthropometric parameters showed difference in the mean weight, BMI, WC and body fat in normal $(60.01 \pm 10.02 \mathrm{~kg}, 22.23 \pm 4.05$ $\mathrm{kg} / \mathrm{m}^{2}, 0.84 \pm 0.21 \mathrm{~cm}, 33.40 \pm 11.12 \%$ ) respectively, and obese $\left(98.80 \pm 10.42 \mathrm{~kg}, 36.44 \pm 1.10 \mathrm{~kg} / \mathrm{m}^{2}\right.$, $1.65 \pm 0.02 \mathrm{~cm}, 44.1 \pm 10.20 \%$ ) respectively (Table 1).

\subsection{Questionnaires}

Questionnaires of hunger and satiety score showed a significant difference in the mean of hunger and satiety in normal $\left(6.0^{*} \pm 1.23\right)$ and while in obese $\left(7.2^{*} \pm 1.22\right)$ respectively, at 0.05 . Food craving and preference score for unhealthy food showed a significant difference in the mean in normal $(4.99 \pm 1.04)$ while in obese $(6.22 \pm 1.03 * *)$ respectively, at 0.01 . As well as food craving and preference score for healthy food showed a significant difference in the mean in normal $(7.10 \pm 1.02)$ while in obese $\left(5.10 \pm 1.31^{* *}\right)$ respectively, at 0.01 (Table 2).

\subsection{Obesity and Chronic Diseases}

Information on chronic diseases obtained from the questionnaire where the participants were asked to respond (yes/no) to the question "Have a doctor ever said that you have thyroid problems, infertility, vitamin D deficiency, kidney problems, bone pain and general weakness. The participants were asked to report whether they had suffered from any pain. Based on answers the participants were subdivided into two groups, and the number of pain and chronic diseases recorded in Table 3.

Table 1 General Characterization of Inclusion criteria of 100 female's participants.

\begin{tabular}{lll}
\hline Particulars & 100 female & \\
\hline Age & 17 to 35 year & \\
\hline & Normal Weight $(70$ female) & Obese (II) (30 female) \\
\hline Weight $(\mathrm{kg})$ & $60.01 \pm 10.02$ & $98.80 \pm 10.42$ \\
BMI $\left(\mathrm{kg} / \mathrm{m}^{2}\right)$ & $22.23 \pm 4.05$ & $36.44 \pm 1.10$ \\
Waist circumference WC $(\mathrm{cm})$ & $0.84 \pm 0.21$ & $1.65 \pm 0.02$ \\
BF $(\%)$ & $33.40 \pm 11.12$ & $44.1 \pm 10.20$ \\
\hline
\end{tabular}

Data was expressed using Mean $\pm \mathrm{SD}$.

Table 2 Comparison between a normal and an obese subject according to nutritional history and food frequency questionnaires.

\begin{tabular}{lll}
\hline & Normal Weight & Obese(II) \\
\hline Questionnaires of hunger and satiety score & $6.01^{*} \pm 1.23$ & $7.2^{*} \pm 1.22$ \\
Food Craving and Preference for unhealthy food scores. & $4.99 \pm 1.04$ & $6.22 \pm 1.03^{* *}$ \\
Food Craving and Preference for healthy food scores & $7.10 \pm 1.02$ & $5.10 \pm 1.31^{* *}$ \\
\hline
\end{tabular}

Data was expressed using Mean \pm SD.

*: Significant at 0.05 between normal and obese.

**: Significant at 0.01 between normal and obese. 
Table 3 Obesity and chronic diseases.

\begin{tabular}{|c|c|c|c|c|c|}
\hline \multirow{2}{*}{ Particular (number) } & \multicolumn{2}{|c|}{ Normal Weigh } & \multicolumn{2}{|c|}{ Obese II } & \multirow{2}{*}{$\mathrm{P}$} \\
\hline & No. & $\%$ & No. & $\%$ & \\
\hline Thyroid problems (number) & 0 & 0.0 & 28 & 93.3 & $<0.001^{*}$ \\
\hline Infertility (number) & 0 & 0.0 & 5 & 16.7 & $0.002^{*}$ \\
\hline Vitamin D deficiency (number) & 10 & 14.3 & 20 & 66.7 & $<0.001^{*}$ \\
\hline General weakness (number) & 10 & 14.3 & 30 & 100.0 & $<0.001^{*}$ \\
\hline Kidney problems (number) & 2 & 2.9 & 5 & 16.7 & $0.024^{*}$ \\
\hline Bone pain (number) & 10 & 14.3 & 30 & 100.0 & $<0.001^{*}$ \\
\hline
\end{tabular}

*: Statistically significant at $\mathrm{p} \leq 0.05$.

\section{Discussion}

Regarding lifestyle, it means basic account day-to-day habits that we rely on that can speed up or turn off our metabolism that lead to long or short term weight and disease gains. University students are still not safe from many of the negative effects resulting from their lifestyle during several years of university study that called malnutrition that includes both under-nutrition and over-nutrition, both possibly invited many diseases [24, 25]. Undernutrition associated with a poor economic situation, ignorance of food culture knowledge, hospitalization, and poor health status, while over-nutrition associated with increased energy dense foods and deficient in certain essential nutrients. Modern lifestyle and environmental influences including inappropriate dietary habits, sedentary lifestyle that can finally lead to obesity, cardiovascular disease, hypertension, diabetes, arthritis, gout, fibromyalgia, cancer, vitamin D deficiency, kidney problems, general weakness, thyroid problems, infertility and others [24, 25].

Our result showed that a significant differences in questionnaires of hunger and satiety as well as food craving and preference for healthy and unhealthy food scores in both normal and obese groups. These data associated with presences of a certain type of diseases and differences in anthropometric measurements such as BMI, WC, and body fat in obese adult subjects as compared to the normal group. These mean that our anthropometric body measurements depended on lifestyle and food choices. The craving and preference for unhealthy food and beverage such as diet drinks, artificial sweeteners, chips, Pepsi Cola and sugary drinks, fast foods including pizza, French fries, cake doughnuts and cookies, and a traditional staple food called "kabsa" that includes white rice, saturated fat, and red meat or fried chicken with skin, showed higher significant elevation in obese grope more than normal. Otherwise food craving and preference includes a healthy food such as fruit, vegetable, fish, low-fat milk products and whole grain, showed higher significant elevation in normal grope as compared to obese. Students with abnormal BMI have shown a higher prevalence of chronic diseases such as (Vitamin D deficiency, Kidney problems, bone pain, General weakness, Thyroid problems, Infertility) compared to normal BMI students. These results may be due to the composition of unhealthy food that relying on it in the obese group. For example, artificial food and beverages such as diet drinks, artificial sweeteners, chips, Pepsi cola and sugary drinks mainly contain MSG (Monosodium glutamate), is an amino acid that used as a flavor enhancer. Glutamate is a neurotransmitter and a component of an antioxidant GSH (glutathione). The toxicity of over level of glutamate led to calcium flooding and overstimulation of nerve cells. Glutamate can promote oxidative stress and deplete GSH and other antioxidant levels and led to many types of diseases [4, 26]. Artificial sweeteners such as sugar and sugar alcohols are considered nutritive sweeteners lower in calories, but they are not calorie free. The sugar that labeled as sugar-free, alcohols or polyols, contain fewer calories than table sugar and led to decrease glycemic response, dental 
cavities, and lowering caloric intake. These sugar supply low calories than other because they have incomplete absorption way in our body, that lead to abdominal gas, diarrhea, and other problems [27-31]. Otherwise, consumption of sugar-sweetened beverages causes metabolic disorders, such as obesity. Aspartame, an artificial sweetener present in diet drinks especially Pepsi Cola, is a low calorie, has many side effects including liver, kidney, brain disorder, Blurred Vision, Headaches, Seizures, and increases hunger [32, 33]. Methanol, aspartame by-products, led to aspartame toxicity, an increase in plasma concentrations of Phe (phenylalanine) and aspartic acid that are altering the brain's neural chemical composition that link between epilepsy and brain tumors [34-36]. Our results agree with some investigators that reported that Cola intake is a risk factor for chronic kidney diseases that mediate the negative effects on bone metabolism [37, 38].

The reasons for renal dysfunction include increased glucose load, phosphate intake, and carbonyl stress resulted from chronic cola consumption. Cola consumption is a source of nutritional melanoidins; that contributes to kidney damage and bone diseases $[39,40]$.

Avoid eating empty calories such as zero diet drinks, artificial sweeteners to help lose fat and gain muscle does not work because foods that contain empty calories are simply those that contain a lot of energy but little nutrition such as white bread, pasta, and rice. Scientist recommends that nutrient-dense food such as fruit and vegetables be substituted for empty-calorie food led to decrease body fat and hunger. These results agree with our results, the Food Craving and Preference for a healthy food scores in normal group showed significations elevation than obese group, that lead to decrease anthropometric measurements such as BMI, WC, Body fat, and questionnaires of hunger and satiety, food craving and preference for unhealthy food scores in adult normal as compared to obese subjects.

Another explanation for our results discusses the association between BMI and a certain type of diseases is the presence of a certain type's fat in subject relying food. French fries, potato chips and sugary drinks sodas and soft drinks as well as red and processed meats, chicken, other potato sides, sweets and desserts, refined grains, packaged juices, and butter, are long-term weight gain foods causes overweight or obese. Saturated fat associated with of formation of visceral fat or abdominal fat, increased cholesterol (bad and total), high blood pressure, cancer, stroke, Alzheimer's disease, atherosclerosis, and other forms of the cardiovascular disease [41, 42]. A study by Debette et al. (2010) [43] found that associated with higher volumes of visceral fat, decrees in brain volumes and increased risk of dementia. Scientists reported that visceral fat pumps out immune system chemicals called cytokines such as tumor necrosis factor and interleukin-6 - that can increase the risk of cardiovascular disease and have deleterious effects on cells' sensitivity to insulin, blood pressure, and blood clotting.

Visceral fat is important metabolic tissues that secrete factors systemically that alter the immunological, metabolic and endocrine center and contributed to insulin resistance [44]. Scientists reported that, leptin, a hormone released by the belly fat, may have some adverse effect on the brain. Leptin plays a role in appetite regulation but also in learning and memory. Diabetes, arthritis, gallstones, blood pressure, gout, sleep apnea and a certain type of kidney, liver and cancer diseases are obesity related diseases. Our results agree with other that reported that eating white or refine carbohydrates increases bad intestinal bacterium that associated to unhealthy food addiction as well as causes many problems such as nervous system inflammation, sleep disturbance, stress, chronic fatigue syndrome, fibromyalgia, and restless legs syndrome $[45,46]$.

Our results showed that increase presences of infertility ratio in the obese group as compared to normal, these mean that body fat plays a vital role in female reproduction. Both excess and defect of body 
fat lead to reproductive disorders [47-49]. In overweight and obese women, an increase in fat cells contributed to the elevation of leptin and insulin levels that cause irregular ovulation. PCOS (polycystic ovarian syndrome) is a link between obesity, excess insulin production, and infertility, that associated with irregular menstrual cycles, anovulation (decreased or stopped ovulation) [50, 51].

Our findings showed that there is vitamin D deficiency in the normal group that may be due to avoiding exposure to the sun. As well as vitamin D deficiency in obese female higher than that in normal group. The results may be due to avoiding exposure to solar UV (ultraviolet) radiation that is indispensable for the cutaneous synthesis of vitamin D3 that led to decrease plasma concentrations of 25-hydroxyvitamin $\mathrm{D}[25(\mathrm{OH}) \mathrm{D}][52]$. The production of the active vitamin $\mathrm{D}$ metabolite, 1, 25-dihydroxyvitamin D $[1,25(\mathrm{OH}) 2 \mathrm{D}]$, is enhanced, and thus, its higher concentrations exert negative feedback control on the hepatic synthesis of 25(OH)D [53]. It has reported that the metabolic clearance of vitamin D may increase in obesity, possibly with enhanced uptake by adipose tissue [54]. Some investigators reported that there is an expression in vitamin D-metabolizing enzymes in human adipose tissue [55-58]. Vitamin D deficiency accompanied by obesity, visceral obesity, hypertriglyceridemia [55-58].

Obesity and starvation have different effects on normal hormones physiology including cortisol and thyroid hormone [58]. Our results showed that there was a high increase in thyroid problem in the case of the obese female; this indicates that obesity and the followed lifestyle affected body physiological hormone, consequently physiological metabolism including bone metabolism and female infertility. Where thyroid hormones regulate metabolism - the way the body uses energy - and affect nearly every organ in the body. Too much thyroid hormone is called hyperthyroidism and can cause many of the body's functions to speed up. Too little thyroid hormone is called hypothyroidism and can cause many of the body's functions to slow down.

Human emptied the food from its content of life basic, human-made food just like the kinds of stuff puts in his stomach to hold the attic of his life, without worries if his body accept this food or not. Hence we felt that common conditions, loss of appetite, degeneration of powers, digestive disorder, disturbance of stomach, flatulence, and mother intestines, increase of diseases such as cancer ,diabetes, vitamin $d$ deficiency, kidney problems, bone pain, general weakness, thyroid problems, infertility and other, all of which are phenomena has long pushed people to clinics doctors seeking treatment. They do not know that they are the ones who have caused for themselves these ills and pains, by go against Mother Nature. The nature of our return pays a price to go against its principles and rules dearly. The first and important step in feeling well is lifestyle management through a challenge to removing the triggers that trigger autoimmunity. Spreading awareness of the lifestyle changes that can impact autoimmunity is my personal mission. Through lifestyle challenge interventions like removing food, additive, sensitivities, balancing the gut flora bacteria and increase good one, cover nutrient depletions and removing triggers, many individuals, including myself, have been able to eliminate symptoms, reduce and even reverse autoimmunity $[45,59]$.

\section{Conclusion}

The conclusions of the present study were that reducing in high-acidic diet, fast food, animal fat, refined carbohydrate, red meat, eating out season and increase in fruits, raw or steamed vegetables, fish, white meat, whole grains, in diet to avoid invite diseases such as weight gain cancer, and diabetes. The new challenge is to understand interactions between biological processes and food. Developing a healthy relationship with food can help you maximize fitness, decreased obesity and avoid diseases while enjoying everything you eat. So we shall look at the physical, 
biochemical and psychological aspects of eating. It considers as human life equation which breaking by bad uses. So to avoid undesirable consequences choices, the human must make a choice the return, to Mother Nature.

\section{Reference}

[1] Bingham, S. A, Welch, A. A., McTaggart, A., et al. 2001. "Nutritional Methods in the European Prospective Investigation of Cancer in Norfolk." Public Health Nutrition 4 (3): 847-58.

[2] Bolton, S. C., and Milne, A. C. 1991. "FFQ Versus Weighed Intake Data on Scottish Men.” Proc. Nutr. Soc. 50: 36A.

[3] Cade, J., Thompson, R., Burley, V., and Warm, D. 2002. "Development, Validation and Utilization of Food Frequency Questionnaires-Review." Public Health Nutrition 5 (4): 567-87.

[4] Hubert, H., Feinlieb, M., McNamara, P., et al. 1983. "Obesity as an Independent Risk Factor for Cardiovascular Disease: A 26-Year Follow up of Participants in the Framingham Heart Study." Circulation 67: 968-77.

[5] Lew., E. 1985. "Mortality and Weight: Insured Lives and the American Cancer Society Studies." An. Intern. Med. 103: 1024-9.

[6] Lenz, M., Richter, T., and Mühlhauser, I. 2009. "The Morbidity and Mortality Associated with Overweight and Obesity in Adulthood." Dtsch Arztebl Int. 106: 641-8.

[7] Sherpa, L. Y., Deji, et al. 2011. "Lipid Profile and Its Association with Risk Factors for Coronary Heart Disease in the Highlanders of Lhasa, Tibet." High Alt. Med. Biol. 12: 57-63.

[8] Standing Committee on the Scientific Evaluation of Dietary Reference Intakes, Food and Nutrition Board, Institute of Medicine. 1997. "Dietary Reference Intakes for Calcium, Phosphorous, Magnesium, Vitamin D, and Fluoride." National Academy Press.

[9] Shils., M., Olson, J., Shike, M., and Ross, C. A. 1999. "Modern Nutrition in Health and Disease." Ninth Edition, Lipincott, Williams and Wilkins.

[10] Standing Committee on the Scientific Evaluation of Dietary Reference Intakes, Food and Nutrition Board, Institute of Medicine, 2000. "Dietary Reference Intakes for Vitamin C, Vitamin E, Selenium, and Carotenoids." National Academy Press.

[11] Krahulec, B. 2005. "Obezita a Niektoré Faktory Prostredia Podporujúce Vznik Metabolického Syndrómu." Cardiol 14: 161-5.
[12] Katzmarzyk, P.T., Reeder, B. A., Elliott, S., et al. 2012. "Body Mass Index and Risk of Cardiovascular Disease, Cancer and All-Cause Mortality." Public Health 103: 147-51.

[13] Capuano, V., Bambacaro, A., D’Arminio, T., et al. 2003. "Correlation between Body Mass Index and Others Risk Factors for Cardiovascular Disease in Women Compared with Men.” Arch. Chest Dis. 60: 295-300.

[14] Zhu, S. K., Wang, Z. M., Heshka, S., et al. 2002. "Waist Circumference and Obesity-Associated Risk Factors among Whites in the Third National Health and Nutrition Examination Survey: Clinical Action Thresholds.” Am. J. Clin. Nutr. 76: 743-9.

[15] Janssen, I., Katzmarzyk, P. T., and Ross, R. 2004. "Waist Circumference and Not Body Mass Index Explains Obesity-Related Health Risk." Am. J. Clin. Nutr. 79: 379-84.

[16] Lean, M. E., Han, T. S., and Morrison, C. E. 1995. "Waist Circumference as a Measure for Indicating Need for Weight Management." BMJ 311: 158-61.

[17] Womble, L., Wadden, T., Chandler, J., and Martin, A. 2003. "Agreement between Weekly vs. Daily Assessment of Appetite." Appetite 40: 131-5.

[18] Foster, G. D., Wadden, T. A, Peterson, F. J., Letizia, K. A., Bartlett, S. J., and Conill, A. M. 1992. "A Controlled Comparison of Three Very-Low-Calorie Diets: Effects on Weight, Body Composition, and Symptoms." Am. J. Clin. Nutr. 55: 811-7.

[19] White, M. A., Whisenhunt, B. L., Williamson, D. A., Greenway, F. L., and Netemeyer, R. G. 2001. "Development and Validation of the Food Craving Inventory."

[20] Wadden, T. A., Stunkard, A. J., Day, S. C., Gould, R. A., and Rubin, C. J.,1987. "Less food, Less Hunger: Reports of Appetite and Symptoms in a Controlled Study of a Protein-Sparing Modified Fast." Int. J. Obes. 11: 239-49.

[21] Geiselman, P. J., Anderson, A. M., Dowdy, M. L.,West, D. B., Redmann, S. M., and Smith, S. R. 1998. "Reliability and Validity of a Macronutrient Self-Selection Paradigm and a Food Preference Questionnaire." Physiology and Behavior 63 (5): 919-28.

[22] Buffenstein, R., Poppitt, S. D., McDevitt, R. M., and Prentice, A. M. 1995. "Food Intake and the Menstrual Cycle: A Retrospective Analysis, with Implications for Appetite Research.” Physiology and Behavior 58 (6): 1067-77.

[23] Dye, L., and Blundell, J. E. 1997. "Menstrual Cycle and Appetite Control: Implications for Weight Regulation." Human Reproduction 12 (6): 1142-51.

[24] Hertelyova, Z., Salaj, R., Chmelarova, A., Dombrovsky, P., Dvorakova, M. C., and Kruzliak, P. 2014. "The 
Association between Lipid Parameters and Obesity in University Students." J. Endocrinol Invest. DOI 10.1007/s40618-015-0240-8.

[25] The Caroline Walker Trust. 2004. "Eating Well for Older People." Practical and Nutritional Guidelines for Food in Residential and Nursing Homes and for Community Meals. 2nd ed." The Caroline Walker Trust.

[26] Sampath, P. 2014. "How Safe Is Monosodium Glutamate? Exploring the Link to Obesity, Metabolic Disorders, and Inflammatory Disease." J. Med. Food 17 (5): 1 .

[27] Abou-Donia, M. B. J. 2008. "Splenda Alters Gut Microflora and Increases Intestinal P-Glycoprotein and Cytochrome P-450 in Male Rats." Toxicol Environ Health 71 (21): 1415-29.

[28] Bell, W. 2002. "Carcinogenicity of Saccharin in Laboratory Animals and Humans: Letter to Dr. Harry Conacher of Health Canada." Int. J. Occup. Environ. Health 8 (4): 387-393.

[29] Bertino, M. 1982. "Long-Term Reduction in Dietary Sodium Alters the Taste of Salt." Am. J. Clin. Nutr. 36: 1134-44.

[30] Betty, K. 2014. "Can You Get Something for Nothing?" MedicineNet, Inc. http://www.medicinenet.com/artificial_sweeteners/page 13.htm.

[31] Duyuff, R. L. 2006. "Complete Food and Nutrition Guide." John Wiley and Sons, Inc,.

[32] Stephen, D., Antona, C. K., Martina, H. H., et al. 2010. "Effects of Stevia, Aspartame, and Sucrose on Food Intake, Satiety, and Postprandial Glucose and Insulin Levels." Appetite 55 (1): 37-43.

[33] Michael, G. T., and Annette, M. A. 1990. "Oral Stimulation with Aspartame Increases Hunger." Physiology and Behavior 47 (3): 555-9.

[34] Meldrum, B. S. 1993. "Amino Acids as Dietary Excitotoxins: A Contribution to Understanding Neurodegenerative Disorders.” Brain Res. 18: 293-314.

[35] Lajtha, A., Reilly, M. A., and Danlop, D. S. 1994. "Aspartame Consumption: Lack of Effects on Neural Function." J. Nutr. Biochem. 5: 226-83.

[36] Tschanz. C., Butchko, H. H., Stargel, W. W., and Kotsonis, F. N. (Editors). 1996. "The Clinical Evaluation of a Food Additive: Assessment of Aspartame.” Boca Raton, CRC Press, 308.

[37] Saldana, T. M., Basso, O., Darden, R., and Sandler, D. P. 2007. "Carbonated Beverages and Chronic Kidney Disease.” Epidemiology 18: 501-6.

[38] Ogur, R., Uysal, B., Ogur, T., Yaman H., Oztas, E., Ozdemir, A., and Hasde, M. 2007. "Evaluation of the Effect of Cola Drinks on Bone Mineral Density and Associated Factors." Basic Clin. Pharmacol. Toxicol.
100: 334-8.

[39] Ahmed, N., Mirshekar-Syahkal, B., Kennish, L., Karachalias, N., Babaei-Jadidi, R., and Thornalley, P. J. 2005. "Assay of Advanced Glycation Endproducts in Selected Beverages and Food by Liquid Chromatography with Tandem Mass Spectrometric Detection." Mol. Nutr. Food Res. 49: 691-9.

[40] Koschinsky, T., He, C. J., Mitsuhashi, T., Bucala, R., Liu, C., Buenting, C., Heitmann, K., and Vlassara, H. 1997. "Orally Absorbed Reactive Glycation Products (Glycotoxins): An Environmental Risk Factor in Diabetic Nephropathy." Proc. Natl. Acad. Sci. USA 94: 6474-9.

[41] Carey, D. G. P. 1998. “Abdominal Obesity.” Current Opinion in Lipidology 9 (1): 35-40.

[42] Razay, G., Vreugdenhil, A., and Wilcock, G. 2006. "Obesity, Abdominal Obesity and Alzheimer Disease." Dementia and Geriatric Cognitive Disorders 22 (2): 173-4.

[43] Debette, S., Beiser, A., Hoffmann, U., et al. "Visceral Fat Is Associated with Lower Brain Volume in Healthy Middle-Aged Adults." Annals of Neurology 68 (2): 136-44.

[44] Claire, L., Donohoe, S. L., Doyle, and John V. R. 2011. "Visceral Adiposity, Insulin Resistance and Cancer Risk.” Diabetology and Metabolic Syndrome 3: 12.

[45] Hamouda, F. A., and Abou El, Noeman, SEl Dien, A. 2016. "Effects of 6-Month Weight Loss New Program on Anthropometric Measurements and Biological Profile." Journal of Pharmacy and Pharmacolog 4 (1): 23-38.

[46] Leo, G. 2014. "The Gut Microbiome and the Brain." J. Med. Food 17 (12): 1261-72.

[47] Green, B. B., Weiss, N. B., and Daling, J. R. 1988. "Risk of Ovulatory Infertility in Relation to Body Weight." Fertil Steril 50: 721.

[48] Bates, G. W., Bates, S. R., and Whitworth, N. S. 1982. "Reproductive Failure in Women Who Practice Weight Control." Fertil Steril 37: 373.

[49] Bates, G. W., and Whitworth, N. S. 1982. "Effect of Body Weight Reduction on Plasma Androgens in Obese, Infertile Women." Fertil Steril 38: 406.

[50] Stefan, S., Du Plessis, S., Cabler, D. A. M., et al., 2010. "The Effect of Obesity on Sperm Disorders and Male Infertility." Nat. Rev. Urol. 7: 153-61.

[51] Sharpe, R. M., and Franks, S. 2002. "Envirinment, Lifestyle and Infertility-An Inter-Generational Issue." Nat. Cell Biol. 4 (Suppl): 33-40.

[52] Jacobo, W., Lois, Y. M., Tai, C. C., Z. L., and Michael, F. H. 2000. "Decreased Bioavailability of Vitamin D in Obesity1.” Am. J. Clin. Nutr. 72: 690-3.

[53] Bell, N. H., Epstein, S., Greene, A., Shary, J., Oexmann, 
M. J., and Shaw, S. 1985. "Evidence for Alteration of the Vitamin D-Endocrine System in Obese Subjects." J. Clin. Invest. 76: 370-3.

[54] Liel, Y., Ulmer, E., Shary, J., Hollis, B. W., and Bell, N. H. 1988. "Low Circulating Vitamin D in Obesity." Calcif Tissue Int. 43: 199-201.

[55] Khanh, vinh quốc. L., and Lan, T. H. N. 2013. "The Beneficial Role of Vitamin D in Obesity: Possible Genetic and Cell Signaling Mechanisms." Vinh quốc Luong and Nguyễn Nutrition Journal 12: 89.

[56] Lee, S. H., Kim, S. M., Park, H. S., Choi, K. M., Cho, G. J., et al. 2012. "Serum 25-Hydroxyvitamin D Levels, Obesity and the Metabolic Syndrome among Korean Children." Nutr. Metab. Cardiovasc. Dis. Epub Ahead of Print.
[57] Saliba, W., Barnett-Griness, O., Rennert, G., 2012. "The Relationship between Obesity and the Increase in Serum $25(\mathrm{OH})$ D Levels in Response to Vitamin D Supplementation." Osteoporos Int. Epub Ahead of Print.

[58] Douyon, L., and Schteingart, D. E. 2002. "Effect of Obesity and Starvation on Thyroid Hormone, Growth Hormone, and Cortisol Secretion." Endocrinol Metab. Clin. North Am. 31 (1): 173-89.

[59] Dana Trentini. 2013. “Hashimoto's Thyroiditis: Lifestyle Interventions for Finding and Treating the Root Cause." Prose Theme on Genesis Framework Word Press. Accessed September 16, 2013. http://hypothyroidmom.com/hashimotos-thyroiditis-life style-interventions-for-finding-and-treating-the-root-ca use/. 